\title{
Human papillomaviruses: a growing field
}

\author{
Denise A. Galloway ${ }^{1}$ \\ Human Biology Division, Fred Hutchinson Cancer Research Center, Seattle, Washington 98109, USA
}

\begin{abstract}
A combination of functional studies on human papillomavirus (HPV) oncoproteins and epidemiological studies on persistence of HPV infection firmly established a role for HPV in the etiology of cervical cancers. Understanding the viral life cycle of HPVs has been more difficult. In this issue of Genes \& Development, Wang et al. (pp. 181194) describe an efficient method to propagate infectious HPV in differentiating epithelium, providing clear evidence for temporal separation of viral and cellular replication.
\end{abstract}

\section{Propagating HPVs in culture}

Full-length human papillomavirus (HPV) genomes were first molecularly cloned in the early 1980s (for review, see de Villiers et al. 2004). Transfection of their circularized genomes into primary human keratinocytes (PHKs) resulted in very limited replication, and cells that maintained episomal HPV were at a growth disadvantage compared with PHKs that either lost the viral genome or cells in which the HPV genome integrated into host chromosomes (Mungal et al. 1992). Examination of the patterns of viral gene expression in naturally infected tissues-i.e., plantar warts, condyloma, and cervical intraepithelial neoplasias (CIN)-provided a likely explanation (for review, see Baker 1993). Whereas some of the early genes-E6, E7, E1, and E2-were expressed in undifferentiated basal and suprabasal cells, transcription of other early genes, E1^E4, and the viral capsid genes, L1 and L2, were restricted to the more differentiated peripheral layers of the epithelium, as was HPV DNA amplification.

Adaptation of organotypic culture techniques, also known as rafts, provided the basis for propagation of HPVs, and steady improvements in methodology have resulted in efficient propagation of HPV viruses. Briefly, fibroblasts are mixed into a collagen matrix; PHKs are seeded on top of the matrix and grown to confluence, and when the structure is lifted to an air-liquid interface, the PHKs differentiate to form a full-thickness stratified epithelium. This approach was initially used to study

[Keywords: Human papillomavirus infection program; organotypic cultures of primary human keratinocytes; Cre-loxP-mediated recombination in vivo; cell cycle regulation; immortalization- and replicationdefective E6 mutant; p53 protein stabilization]

${ }^{1}$ Correspondence.

E-MAIL dgallowa@fhcrc.org; FAX (206) 667-5815.

Article is online at http://www.genesdev.org/cgi/doi/10.1101/gad.1765809. the phenotype of HPV immortalized cell lines (McCance et al. 1988; Blanton et al. 1991) and the contribution of the immortalizing genes E6 and E7 to growth deregulation (Blanton et al. 1992; Halbert et al. 1992; Cheng et al. 1995). In a few cases, cell lines were established from CIN lesions that harbored episomal HPV genomes, and these lines-e.g., W12 and CIN-612-allowed viral amplification and packaging when grown in organotypic cultures (Stanley et al. 1989; Sterling et al. 1990; Bedell et al. 1991). The yield of virus per CIN-612 raft culture was high, and the virions obtained from these cultures were able to infect keratinocytes, although infection of established cell lines such as $\mathrm{HaCaT}$ was much more robust than infection of primary keratinocytes (Ozbun 2002). More efficient methods to transfect PHKs with HPV genomes and modifications to the organotypic culture conditions provided the first opportunities to propagate wild-type and mutated HPV genomes, thus opening the door to papillomavirus genetics (Dollard et al. 1992; Meyers et al. 1992). The ability to generate HPV16, HPV18, and HPV31 virions in organotypic rafts from transfected DNAs templates has been previously shown (Frattini et al. 1996; Meyers et al. 1997; Flores et al. 2000). These studies have allowed for genetic analyses of HPV functions during the viral life cycle, although the yields of virions from stably transfected cells are low. Introduction of adenovirus recombinants encoding the HPV genome flanked by lox $\mathrm{P}$ sites plus Cre recombinase into PHKs grown in raft cultures also provided a means to produce infectious HPV virions (Lee et al. 2004).

In parallel efforts, other groups took the approach of generating high-titer pseudovirus by transient cotransfection of 293 TT cells with plasmids that expressed marker genes along with codon-modified versions of the HPV capsid genes (Buck et al. 2004). This method was extended to package intact HPV genomes (Pyeon et al. 2005). As with the virions produced in organotypic culture, these pseudoviruses, or "293 packaged HPVs," efficiently infect a variety of established cell lines, even mouse cervical epithelium in vivo (Roberts et al. 2007), yet only poorly infect PHKs.

The accompanying study by Wang et al. (2009) describes a new, improved method for generating infectious HPV virions. Cotransfection of PHKs with a plasmid containing the HPV18 genome into which lox P sites and the neomycin-resistance gene were inserted into the viral noncoding region, along with a plasmid containing a NLS-tagged Cre recombinase, resulted in efficient 
establishment of cells harboring 2000-5000 copies of the HPV18 genome. HPVs normally infect basal keratinocytes, likely at sites of wounding, providing an environment that allows the establishment of episomal DNA at $\sim 50$ copies per cell, which is also seen in the stably transfected PHKs. The superphysiological levels of HPV plasmid obtained in this system may influence viral replication and assembly. When $2.5 \times 10^{5}$ of the G418 selected PHKs were grown in organotypic culture, viral yields of $\sim 3 \times 10^{8}$ to $5 \times 10^{8}$ were obtained. What is most striking, and in contrast to other studies, virions obtained from these cultures efficiently infected PHKs at a multiplicity of infection (MOI) of $<50$, resulting in expression of spliced viral mRNAs and induction of host cell DNA synthesis. The improvement in infection of PHKs remains unexplained. Wang et al. (2009) postulate that differences in the maturation of viral particles in vivo, compared with the maturation step of pseudoviral capsids in vitro (Buck et al. 2005), may be the explanation, yet this does not explain why virions obtained from other organotypic cultures infect PHKs so poorly. Other factors such as viral type (HPV18 in this method vs. HPV16 or HPV31 in most studies), the PHK stock and infection conditions, the very high copy number of episomal genomes, or the particle-to-infectivity ratio need to be examined in side-by-side comparisons. Whether this method will be generalizable to other HPV types also remains to be seen. Interestingly, although infection of PHKs was efficient, the full life cycle could only be recapitulated with high multiplicity infection. This new system for propagating HPVs is providing novel insights into the HPV life cycle (Fig. 1).

\section{Viral replication in G2 or pseudo-S phase}

The papillomaviruses do not encode the enzymatic machinery needed for their replication; instead, the E7 protein induces entry into S phase of normally quiescent suprabasal cells (Munger et al. 2001). Viral genomes in which E7 was mutated failed to induce cellular proliferation and did not undergo viral genome amplification
(Thomas et al. 1999; Flores et al. 2000). E7 causes cells throughout the epithelial layer to undergo unscheduled DNA synthesis as measured by markers such as PCNA, MCMs, cyclin A, and uptake of BrdU. While it is reasonable to imagine that this would provide a suitable milieu for concurrent viral DNA replication, previous studies had demonstrated a separation between cellular and viral replication compartments (Middleton et al. 2003; Nakahara et al. 2005). Wang et al. (2009) provide clear evidence to support this idea. Whereas PCNA and cyclin A expression labeled HPV18-containing cells at all layers of the epithelium, a probe to detect amplified HPV18 DNA was restricted to the more peripheral layers of the epithelium (Figs. 3D and 5D in Wang et al. 2009). Moreover, replication of host and viral DNA was temporally separable. Examining cultures at different days postrafting showed that induction of cellular DNA synthesis was rapid and was diminishing by day 12 , whereas almost no viral DNA amplification could be detected until day 12 and persisted abundantly at day 14, a time at which cellular replication could only be seen in scattered basal cells (Fig. 4 in Wang et al. 2009). The evidence that viral DNA replication initiates in G2-arrested cells comes from detecting cytoplasmic cyclin B in mid-level epithelial cells colocalizing with a viral DNA probe (Fig. 5E in Wang et al. 2009).

The strategy of arresting cells in G2 is widely used by diverse families of viruses: DNA, RNA, and retroviruses; the mechanisms used and the potential benefit to the viruses are equally diverse and not well understood (Davy and Doorbar 2007). The HPV E4 proteins have been shown to arrest cells in G2. In the case of HPV16 E4, the proposed mechanism is that disruption of cytokeratin networks by $\mathrm{E} 4$ traps active cyclin B/cdc2 complexes in the cytoplasm (Davy et al. 2005). This mechanism may not be conserved among all HPV types, as HPV1 E4 has been proposed to arrest cells in G2 by maintaining the inactivating phosphorylation on cdc2 (Knight et al. 2006). Furthermore, a mutation that disrupted HPV11 E4 did not affect viral replication (Fang et al. 2006). Additionally, the $\mathrm{E} 2$ protein has been proposed to abrogate the mitotic

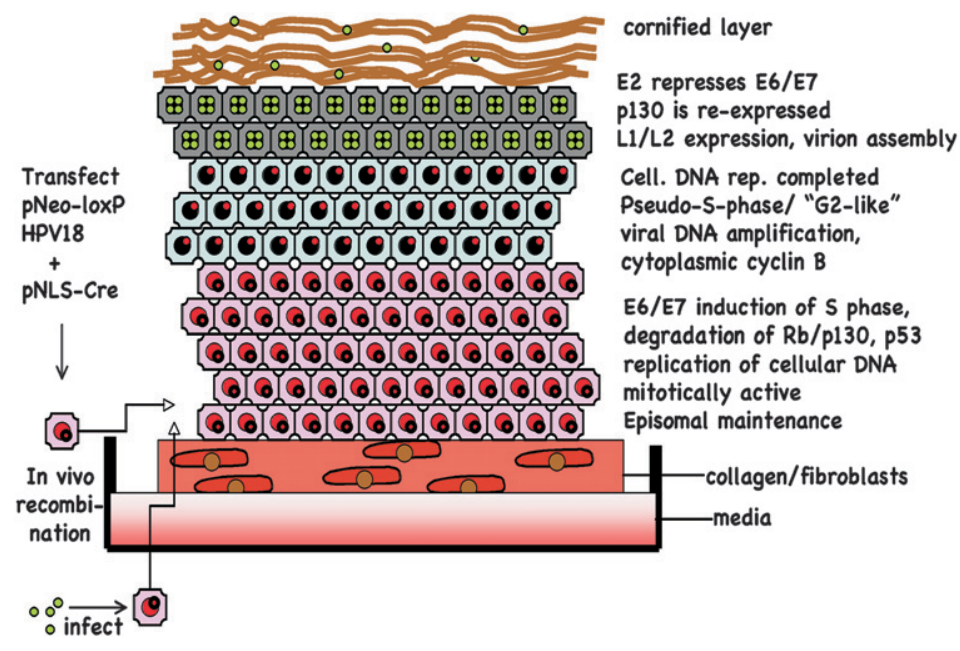

Figure 1. Organotypic culture of human papillomavirus. PHKs are either transfected with plasmids that recombine in vivo to give circularized HPV18, or the PHKs are infected with HPV18 virions produced from organotypic cultures of HPV18-transfected PHKs. The PHKs are placed on a collagen-fibroblast matrix, lifted ("rafted") when confluent and grown for 10-14 d. E7 induces the subrabasal cells to remain in cycle and cellular DNA replication occurs; the HPV genome remains a low-copy episome. When cellular DNA synthesis is complete, there is a brief pseudo-S-like or G2like phase, in which viral DNA replication occurs. The high levels of E2 repress E6/E7 transcription, turning off the markers of S phase, re-expressing p130, and allowing late gene transcription, capsid assembly, and the final stages of epithelial differentiation. 
checkpoint, increasing both viral and cellular replication (Frattini et al. 1997). In fact, a viral mechanism to arrest in G2 may not be essential; instead, the cells may simply finish cellular replication, remain permissive for viral replication, and then differentiate. Which of these mechanisms is biologically relevant remains to be seen.

There is evidence that several DNA viruses establish a pseudo-S-phase state through the continued induction of S-phase genes by expression of SV40 T antigen, adenovirus E1a or HPV E6/E7, in cells arrested in G2. While this is likely true for HPV, it is not entirely clear. On one hand, some colocalization of amplified HPV18 DNA and PCNA was observed (Fig. 3D in Wang et al. 2009). Wang et al. (2009) also suggest that E7 expression is extinguished in the cells with amplified HPV DNA. Because good antibodies for immunostaining of E7 do not exist, E7 expression was assessed indirectly by examining p130 expression, which is normally targeted for degradation by E7 (Helt and Galloway 2003; Zhang et al. 2006). Wang et al. (2009) observed colocalization of p130 and HPV18 DNA in the upper layers of the epithelium (Fig. $5 \mathrm{H}$ in Wang et al. 2009). A plausible explanation is that the day 12 rafts represent a snapshot in which viral DNA replication has been completed, whereas at the initiation of viral DNA synthesis, cells are both arrested in G2 and maintain a replicative environment with continued expression of the biosynthetic and enzymatic machinery required for DNA synthesis. Replication of the viral genome likely occurs in a very short window in a pseudo-S phase or G2-like phase, with the rapid decline of cyclin A, PCNA, and MCMs. The increased expression of E2 may lead to the observed shut-off of E7, which along with differentiation contributes to the re-expression of p130. Maintaining an environment that is permissive for DNA synthesis at a time in which the host cell genome has completed its replication would be a favorable situation for the viral genome to compete.

\section{The role of E6 in the HPV life cycle}

As mentioned above, many DNA viruses induce entry into $S$ phase by deregulating the E2F repressive functions of the $\mathrm{Rb}$ family of pocket proteins. As a consequence, p53 is stabilized through the induction of ARF, which inhibits p53 degradation by Mdm-2. Elevated levels of p53 can lead to apoptosis or cell cycle arrest through the activation of $\mathrm{p} 53$ targets such as Bak or p2 ${ }^{\mathrm{CIP} 1}$. To block these impediments to viral replication, DNA viruses commonly inactivate p53, either directly by sequestration or degradation, or indirectly by inhibiting the function of the p53 transcriptional coactivator p300. The high-risk HPV E6 proteins bind to a cellular ubiquitin ligase, E6AP, and target p53 for degradation (Howley 1996). Mutations in HPV31 E6 that either prevented expression of the full-length E6 gene or prevented its binding to p53 were unable to stably maintain episomes (Thomas et al. 1999).

Similarly, Wang et al. (2009) show that an HPV18 genome mutated in the E6 gene fails to amplify its genome or express capsid proteins (Fig. 6A,D in Wang et al. 2009). Interestingly, E7 expression throughout the epithelium is inferred by the induction of p53 and PCNA (Figs. 6D and 7 in Wang et al. 2009), without a concomitant induction of apoptosis as assessed by no detectable cleaved caspase- 3 . Thus, the investigators conclude that the function of E6 is not to counteract the putative apoptosis-inducing functions of E7. It is certainly possible that the main effects of elevated p53 are growthrepressive by inhibiting cyclin/cdk activity, as reflected in the decreased hyperplasia seen with the E6 mutant. Alternatively, other functions of E6 may be important for the virus life cycle including the activation of caspase-3, caspase-7, and caspase-9, which was shown to be necessary for genome amplification by cleaving the HPV E1 helicase (Moody et al. 2007). Similarly, E6 has been reported to bind to numerous cellular proteins with diverse functions in epithelial polarity, transcription, and genome maintenance, and many of these interactions could affect viral replication and expression of the HPV late genes (Tungteakkhun and Duerksen-Hughes 2008). Studies with mutations in E6 that abrogate p53 binding or more mechanistic studies to implicate p53 in late gene transcription will be necessary. The fact that mutations in the E6 protein often disrupt binding to multiple partners complicates the ability to identify the critical functions associated with a particular function.

\section{Permissive versus abortive infection}

Infection of PHKs seems to be efficient at low multiplicity as judged by detection of spliced E1^E4 RNA, hyperplasia, and induction of PCNA in nearly every cell. Surprisingly, although some HPV DNA amplification was observed at low MOI, only high multiplicity infection, MOI of 800, resulted in robust viral DNA replication and, importantly, expression of the capsid proteins. How high-level DNA amplification is related to the induction of late gene expression is unknown. A trivial explanation is the issue of detection. If immunostaining for L1 is not as sensitive as DNA-fluorescence in situ hybridization to detect viral DNA, then low levels of viral replication may lead to low levels of L1 expression and virion assembly.

Is the observation that low-multiplicity infection fails to result in a productive HPV life cycle a consequence of the methods used to produce and passage virions in culture, or is there a biological counterpart in infection of humans? Studies on the natural history of genital HPVs have shown that the prevalence of HPV infections is very high, even in women with low numbers of sexual partners (Ho et al. 1998; Winer et al. 2003). This suggests that transmission rates are likely to be high, although it has been difficult to accurately assign a number, and implies that most infections result in virion production. However, is it possible that low levels of virus might cause abortive infections? And what is the fate of cells that become infected nonproductively? Can the genomes persist latently in basal cells, or become integrated into cellular DNA resulting in the high-level expression of the 
E6 and E7 oncogenes found in cancers? The fact that seroconversion for HPV L1 antibodies is not detected in everyone in whom HPV DNA can be found (Carter et al. 2000) may reflect that some HPV infections do not result in capsid gene expression.

Unfortunately, organotypic culture of HPV-infected cells cannot provide answers about long-term viral persistence and latency. However, the new method presented by Wang et al. (2009) offers an efficient means to generate high titers of virions and expands the possibilities to probe the molecular and genetic details of the papillomavirus life cycle.

\section{Acknowledgments}

I thank John Doorbar, Lou Laimins, and Paul Lambert for helpful comments. D.A.G. is supported by grants from NCI and NIAID.

\section{References}

Baker, C.C. 1993. The genomes of the papillomaviruses. In Genetic maps: Locus maps of complex genomes (ed. S.J. O'Brien), pp. 134-146. Cold Spring Harbor Laboratory Press, Cold Spring Harbor, NY.

Bedell, M.A., Hudson, J.B., Golub, T.R., Turyk, M.E., Hosken, M., Wilbanks, G.D., and Laimins, L.A. 1991. Amplification of human papillomavirus genomes in vitro is dependent on epithelial differentiation. I. Virol. 65: 2254-2260.

Blanton, R.A., Perez-Reyes, N., Merrick, D.T., and McDougall, J.K. 1991. Epithelial cells immortalized by human papillomaviruses have premalignant characteristics in organotypic culture. Am. J. Pathol. 138: 673-685.

Blanton, R.A., Coltrera, M.D., Gown, A.M., Halbert, C.L., and McDougall, J.K. 1992. Expression of the HPV16 E7 gene generates proliferation in stratified squamous cell cultures which is independent of endogenous p53 levels. Cell Growth Differ. 3: 791-802.

Buck, C.B., Pastrana, D.V., Lowy, D.R., and Schiller, J.T. 2004. Efficient intracellular assembly of papillomaviral vectors. $J$. Virol. 78: 751-757.

Buck, C.B., Pastrana, D.V., Lowy, D.R., and Schiller, J.T. 2005. Generation of HPV pseudovirions using transfection and their use in neutralization assays. Methods Mol. Med. 119: 445-462.

Carter, J.J., Koutsky, L.A., Hughes, J.P., Lee, S.K., Kuypers, J., Kiviat, N., and Galloway, D.A. 2000. Comparison of human papillomavirus types 16,18 , and 6 capsid antibody responses following incident infection. J. Infect. Dis. 181: 1911-1919.

Cheng, S., Schmidt-Grimminger, D.C., Murant, T., Broker, T.R., and Chow, L.T. 1995. Differentiation-dependent upregulation of the human papillomavirus $\mathrm{E} 7$ gene reactivates cellular DNA replication in suprabasal differentiated keratinocytes. Genes \& Dev. 9: 2335-2349.

Davy, C. and Doorbar, J. 2007. G2/M cell cycle arrest in the life cycle of viruses. Virology 368: 219-226.

Davy, C.E., Jackson, D.J., Raj, K., Peh, W.L., Southern, S.A., Das, P., Sorathia, R., Laskey, P., Middleton, K., Nakahara, T., et al. 2005. Human papillomavirus type 16 E1 E4-induced G2 arrest is associated with cytoplasmic retention of active Cdk1/cyclin B1 complexes. J. Virol. 79: 3998-4011.

de Villiers, E.M., Fauquet, C., Broker, T.R., Bernard, H.U., and zur Hausen, H. 2004. Classification of papillomaviruses. Virology 324: 17-27.

Dollard, S.C., Wilson, J.L., Demeter, L.M., Bonnez, W., Reichman, R.C., Broker, T.R., and Chow, L.T. 1992. Production of human papillomavirus and modulation of the infectious program in epithelial raft cultures. Genes \& Dev. 6: 1131-1142.

Fang, L., Budgeon, L.R., Doorbar, J., Briggs, E.R., and Howett, M.K. 2006. The human papillomavirus type $11 \mathrm{E} 1^{\wedge} \mathrm{E} 4$ protein is not essential for viral genome amplification. Virology 351: 271-279.

Flores, E.R., Allen-Hoffmann, B.L., Lee, D., and Lambert, P.F. 2000. The human papillomavirus type $16 \mathrm{E} 7$ oncogene is required for the productive stage of the viral life cycle. J. Virol. 74: 6622-6631.

Frattini, M.G., Lim, H.B., and Laimins, L.A. 1996. In vitro synthesis of oncogenic human papillomaviruses requires episomal genomes for differentiation-dependent late expression. Proc. Natl. Acad. Sci. 93: 3062-3067.

Frattini, M.G., Hurst, S.D., Lim, H.B., Swaminathan, S., and Laimins, L.A. 1997. Abrogation of a mitotic checkpoint by E2 proteins from oncogenic human papillomaviruses correlates with increased turnover of the p53 tumor suppressor protein. EMBO J. 16: 318-331.

Halbert, C.L., Demers, G.W., and Galloway, D.A. 1992. The E6 and E7 genes of human papillomavirus type 6 have weak immortalizing activity in human epithelial cells. J. Virol. 66: 2125-2134.

Helt, A.M. and Galloway, D.A. 2003. Mechanisms by which DNA tumor virus oncoproteins target the $\mathrm{Rb}$ family of pocket proteins. Carcinogenesis 24: 159-169.

Ho, G., Bierman, R., Beardsley, L., Chang, C.J., and Burk, R.D. 1998. Natural history of cervicovaginal papillomavirus infection in young women. N. Engl. J. Med. 338: 423-428.

Howley, P.M. 1996. Papillomavirinae: The viruses and their replication. In Fields virology (eds. B.N. Fields et al.), pp. 2045-2076. Lippincott-Raven Publishers, Philadelphia.

Knight, G.L., Turnell, A.S., and Roberts, S. 2006. Role for Wee1 in inhibition of G2-to-M transition through the cooperation of distinct human papillomavirus type 1 E4 proteins. J. Virol. 80: 7416-7426.

Lee, J.H., Yi, S.M., Anderson, M.E., Berger, K.L., Welsh, M.J., Klingelhutz, A.J., and Ozbun, M.A. 2004. Propagation of infectious human papillomavirus type 16 by using an adenovirus and Cre/LoxP mechanism. Proc. Natl. Acad. Sci. 101: 2094-2099.

McCance, D.J., Kopan, R., Fuchs, E., and Laimins, L.A. 1988. Human papillomavirus type 16 alters human epithelial cell differentiation in vitro. Proc. Natl. Acad. Sci. 85: 7169-7173.

Meyers, C., Frattini, M.G., Hudson, J.B., and Laimins, L.A. 1992. Biosynthesis of human papillomavirus from a continuous cell line upon epithelial differentiation. Science 257: 971973.

Meyers, C., Mayer, T.J., and Ozbun, M.A. 1997. Synthesis of infectious human papillomavirus type 18 in differentiating epithelium transfected with viral DNA. J. Virol. 71: 73817386.

Middleton, K., Peh, W., Southern, S., Griffin, H., Sotlar, K., Nakahara, T., El-Sherif, A., Morris, L., Seth, R., Hibma, M., et al. 2003. Organization of human papillomavirus productive cycle during neoplastic progression provides a basis for selection of diagnostic markers. J. Virol. 77: 10186-10201.

Moody, C.A., Fradet-Turcotte, A., Archambault, J., and Laimins, L.A. 2007. Human papillomaviruses activate caspases upon epithelial differentiation to induce viral genome amplification. Proc. Natl. Acad. Sci. 104: 19541-19546.

Mungal, S., Steinberg, B.M., and Taichman, L.B. 1992. Replication of plasmid-derived human papillomavirus type 11 DNA in cultured keratinocytes. J. Virol. 66: 3220-3224.

Munger, K., Basile, J.R., Duensing, S., Eichten, A., Gonzalez, S.L., Grace, M., and Zacny, V.L. 2001. Biological activities 
and molecular targets of the human papillomavirus E7 oncoprotein. Oncogene 20: 7888-7898.

Nakahara, T., Peh, W.L., Doorbar, J., Lee, D., and Lambert, P.F. 2005. Human papillomavirus type $16 \mathrm{E} 1 \wedge \mathrm{E} 4$ contributes to multiple facets of the papillomavirus life cycle. J. Virol. 79: 13150-13165.

Ozbun, M.A. 2002. Infectious human papillomavirus type 31b: Purification and infection of an immortalized human keratinocyte cell line. J. Gen. Virol. 83: 2753-2763.

Pyeon, D., Lambert, P.F., and Ahlquist, P. 2005. Production of infectious human papillomavirus independently of viral replication and epithelial cell differentiation. Proc. Natl. Acad. Sci. 102: 9311-9316.

Roberts, J.N., Buck, C.B., Thompson, C.D., Kines, R., Bernardo, M., Choyke, P.L., Lowy, D.R., and Schiller, J.T. 2007. Genital transmission of HPV in a mouse model is potentiated by nonoxynol-9 and inhibited by carrageenan. Nat. Med. 13: $857-861$.

Stanley, M.A., Browne, H.M., Appleby, M., and Minson, A.C. 1989. Properties of a non-tumorigenic human cervical keratinocyte cell line. Int. J. Cancer 43: 672-676.

Sterling, J., Stanley, M., Gatward, G., and Minson, T. 1990. Production of human papillomavirus type 16 virions in a keratinocyte cell line. J. Virol. 64: 6305-6307.

Thomas, J.T., Hubert, W.G., Ruesch, M.N., and Laimins, L.A. 1999. Human papillomavirus type 31 oncoproteins E6 and E7 are required for the maintenance of episomes during the viral life cycle in normal human keratinocytes. Proc. Natl. Acad. Sci. 96: 8449-8454.

Tungteakkhun, S.S. and Duerksen-Hughes, P.J. 2008. Cellular binding partners of the human papillomavirus E6 protein. Arch. Virol. 153: 397-408.

Wang, H.-K., Duffy, A.A., Broker, T.R., and Chow, L.T. 2009. Robust production and passaging of infectious HPV in squamous epithelium of primary human keratinocytes. Genes \& Dev. (this issue). doi: 10.1101/gad.1735109.

Winer, R.L., Lee, S.K., Hughes, J.P., Adam, D.E., Kiviat, N.B., and Koutsky, L.A. 2003. Genital human papillomavirus infection: Incidence and risk factors in a cohort of female university students. Am. J. Epidemiol. 157: 218-226.

Zhang, B., Chen, W., and Roman, A. 2006. The E7 proteins of low- and high-risk human papillomaviruses share the ability to target the $\mathrm{pRB}$ family member 130 for degradation. Proc. Natl. Acad. Sci. 103: 437-442. 


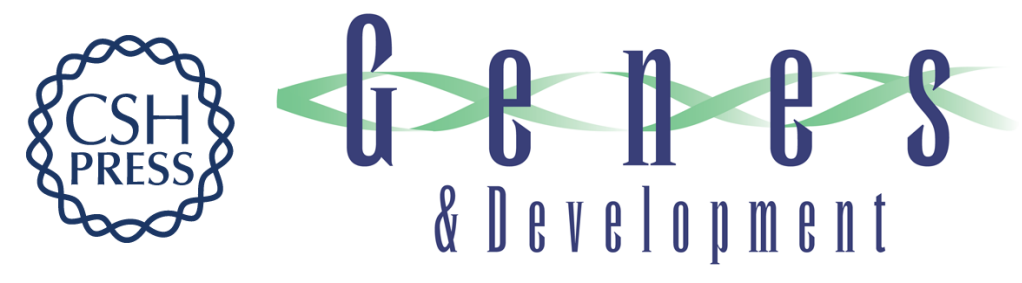

\section{Human papillomaviruses: a growing field}

Denise A. Galloway

Genes Dev. 2009, 23:

Access the most recent version at doi:10.1101/gad.1765809

Related Content Robust production and passaging of infectious HPV in squamous epithelium of primary human keratinocytes

Hsu-Kun Wang, Aaron A. Duffy, Thomas R. Broker, et al.

Genes Dev. January , 2009 23: 181-194

References This article cites 38 articles, 23 of which can be accessed free at:

http://genesdev.cshlp.org/content/23/2/138.full.html\#ref-list-1

Articles cited in:

http://genesdev.cshlp.org/content/23/2/138.full.html\#related-urls

\section{License}

Email Alerting Receive free email alerts when new articles cite this article - sign up in the box at the top

Service right corner of the article or click here.

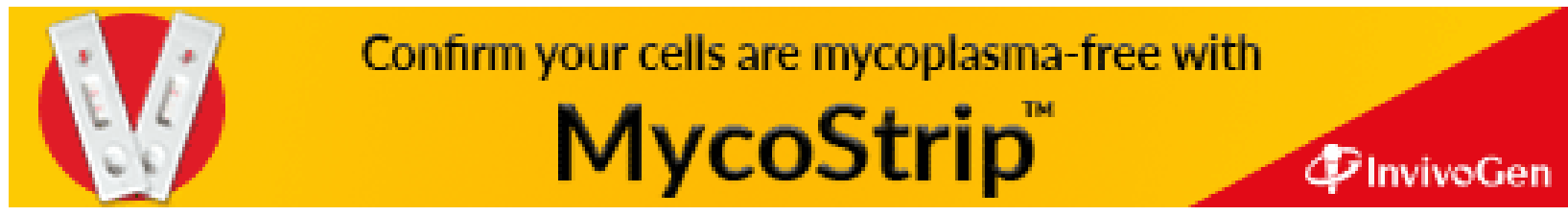

